\title{
Could severe hemophilia A not worse prognosis in the pediatric oncological setting?
}

Lidia Costa ${ }^{1}$, Maria Eduarda Couto ${ }^{2}$, Juliana Moutinho ${ }^{2}$, Ana Ferreira ${ }^{2}$, Susana Roncon ${ }^{2}$, Luísa Santos ${ }^{2}$, Eugénia Cruz ${ }^{1}$, and Sara Morais ${ }^{1}$

${ }^{1}$ Centro Hospitalar Universitário do Porto EPE

${ }^{2}$ Instituto Portugues de Oncologia do Porto Francisco Gentil EPE

August 4, 2020

\begin{abstract}
In spite of existing profuse information regarding hemorrhagic complications of hemophilia, literature is scarce towards the presence of cancer in hemophilia, especially in pediatric patients. There are still many uncertainties concerning these patients' diagnosis and workup. We report here a rare case of two severe aggressive diseases (neuroblastoma and hemophilia A [HA]) concomitantly present in the same pediatric patient. We highlight that the diagnosis of severe HA did not have a negative impact on the patient's oncologic course. This case also illustrates the significance of the enriching cooperation among different specialties and hospitals when caring for the same patient.
\end{abstract}

\section{Hosted file}

MAIN TEXT.doc available at https://authorea.com/users/348623/articles/473834-could-severehemophilia-a-not-worse-prognosis-in-the-pediatric-oncological-setting

\section{Hosted file}

TABLE 1.doc available at https://authorea.com/users/348623/articles/473834-could-severehemophilia-a-not-worse-prognosis-in-the-pediatric-oncological-setting

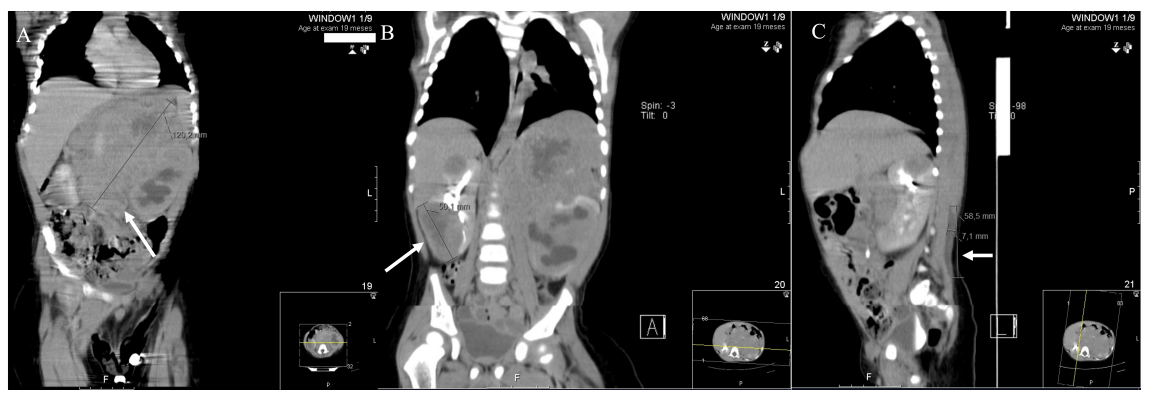

